\title{
Efeito de épocas de semeadura e regimes hídricos em duas cultivares de arroz de sequeiro
}

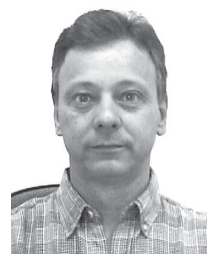

Rogério T. de Faria ${ }^{1}$ \& Marcos V. Folegatti ${ }^{2}$

1 IAPAR, C.P. 481, CEP 86001-970, Londrina, PR. Fone: (43) 376-2422. E-mail: rtfaria@pr.gov.br (Foto)

${ }^{2}$ ESALQ/USP, C.P. 9, CEP 13418-900, Piracicaba, SP. E-mail: mvfolega@carpa.ciagri.usp.br

Protocolo $151-28 / 12 / 2000$

\begin{abstract}
Resumo: Áreas irrigadas requerem cultivo intensivo para maximizar o uso da terra e do sistema de irrigação. A cultura do arroz, devido a resposta à suplementação hídrica, elevado potencial produtivo e compatibilidade fitotécnica com outras culturas, tem elevado potencial para uso em sucessão de cultivos nas áreas irrigadas por aspersão no norte do Paraná. Com o objetivo de se determinar o potencial produtivo, o requerimento hídrico e a duração do ciclo fenológico do arroz, duas cultivares de sequeiro (IAPAR 9 e IAPAR 64) foram semeadas em duas épocas (5 de outubro e $1^{\circ}$ de dezembro) e submetidas a três regimes hídricos (irrigação a tensões de $25 \mathrm{e}$ $70 \mathrm{kPa}$ e sem irrigação) em Londrina, PR. A produtividade foi elevada na semeadura de outubro (5400 a $6000 \mathrm{~kg} \mathrm{ha}^{-1}$ ) e menor na de dezembro (1600 a $4800 \mathrm{~kg} \mathrm{ha}^{-1}$ ) devido à baixa temperatura no final do ciclo, principalmente para a cultivar de ciclo tardio (IAPAR 64); não houve diferença significativa entre os tratamentos irrigados mas a deficiência hídrica decresceu a produção do tratamento sem irrigação, em cerca de 50\%, e atrasou a floração. Concluiu-se, então, que o arroz constitui uma alternativa promissora para sucessão de culturas em projetos de irrigação na região.
\end{abstract}

Palavras-chave: Oryza sativa, irrigação, data de plantio

\section{Effect of planting dates and water regimes on two upland rice cultivars}

\begin{abstract}
Irrigated areas require intensive cropping to maximize use of land and irrigation systems. Rice has a high potential for crop rotation in areas with sprinkler irrigation in northern Paraná State, Brazil, because of its high response to water supply, high potential yield, and compatible phenological cycle with other crops. Potential grain yield, water requirements, and duration of crop cycles were determined for two upland rice cultivars (IAPAR 9 e IAPAR 64), sown at two planting dates (October, $5^{\text {th }}$ and December, $1^{\text {st }}$ ) and maintained under three water regimes (non irrigation and irrigation at tensions equal to 25 and $70 \mathrm{kPa}$ ). Grain yield was high for sowing in October ( 5400 to $6000 \mathrm{~kg} \mathrm{ha}^{-1}$ ) and lower for sowing in December (1600 to $4800 \mathrm{~kg} \mathrm{ha}^{-1}$ ) due to the low temperature at seed filling stages, mostly for the late cultivar (IAPAR 64). No significant differences between irrigated treatments were observed, but water deficit caused a grain yield decrease of up to $50 \%$ and delayed flowering. As a conclusion from these results, upland rice was considered highly appropriate for crop rotation in irrigated areas of Paraná.
\end{abstract}

Key words: Oryza sativa, irrigation, date of sowing

\section{INTRODUÇ̃̃O}

$\mathrm{O}$ arroz de sequeiro é de pequena expressão econômica no Paraná, talvez pelo alto risco conseqüente da total dependência da chuva para suplementação hídrica da cultura. Como o norte do Paraná se localiza em uma região de transição climática, a precipitação apresenta alta variabilidade que, associada a elevada evapotranspiração durante đmaioria das estações do ano, resulta em alta freqüência de períod ss com deficiência hídrica (Caramori \& Faria, 1987). Além disso, condição de baixa retenção de água disponível dos solos da regi to é agravada pelo cultivo intensivo, que acelera a degradação da propriedades físicas do solo devido, principalmente, aos efeitos de compactação e à maior oxidação da matéria orgânica (Vieira et al., 1990). Conseqüentemente, condições de estresse hídrico são freqüentes em qualquer fase de desenvolvimento das culturas.

Pequenas explorações em áreas de meia-encosta no estado do Paraná apresentam condições altamente favoráveis ao uso da irrigação, por se localizarem próximo aos mananciais requerendo, assim, baixa altura de recalque, o que resulta em menor custo do equipamento de irrigação e energia. Porém em áreas irrigadas se requer elevada eficiência de uso do sistema de irrigação, a qual pode ser obtida pela sucessão de cultivos com ciclos compatíveis e alta resposta à suplementação hídrica. 
Para o norte do Paraná, o cultivo do feijão irrigado durante o outono e a primavera foi considerado altamente viável (Faria et al., 1997). A cultura do arroz pode ser uma boa opção para cultivo em sucessão ao feijoeiro, pela sua compatibilidade fitotécnica com aquela leguminosa, por apresentar boa resposta à irrigação suplementar e pelo elevado potencial produtivo (Vieira et al., 1990; Santos \& Costa, 1995).

Melhor eficiência de um sistema de produção pode ser obtida se práticas de manejo adequadas forem utilizadas. Embora seja disponível tecnologia para o cultivo do arroz de sequeiro no Paraná (IAPAR, 1980) há carência de informações para a viabilização do cultivo do arroz em sucessão de culturas em áreas irrigadas, principalmente no que se refere a cultivares adaptadas, requerimentos hídricos da cultura e épocas de semeadura apropriadas.

O arroz é cultivado em regiões tropicais e subtropicais, com cultivares de ciclo precoce (neutras ao fotoperíodo) ou de ciclo tardio (de dias curtos) apresentando melhor desenvolvimento em temperaturas variando entre 22 a $30{ }^{\circ} \mathrm{C}$, durante qualquer estádio de desenvolvimento, porém acima de $17^{\circ} \mathrm{C}$ (De Datta, 1981). A cultura é altamente sensível ao estresse hídrico, principalmente no período entre 20 dias antes e 10 dias após o florescimento (IAPAR, 1980); no florescimento, o estresse hídrico causa drástico decréscimo de produtividade, devido à inibição da polinização e esterilidade das espiguetas (Novero et al., 1985; Ekanayake et al., 1990). Durante o período vegetativo o estresse hídrico reduz a altura da planta, o perfilhamento e a área foliar, além de atrasar o ciclo de cultivo pelo alongamento do período vegetativo anterior à iniciação da panícula (De Datta et al., 1975).

Esse estudo teve como objetivo determinar o potencial produtivo, o requerimento hídrico e as características agronômicas de duas cultivares de arroz de sequeiro, em função de épocas de semeadura e regimes hídricos, visando ao cultivo em áreas irrigadas do norte do Paraná.

\section{MATERIAL E MÉTODOS}

O experimento foi conduzido na Estação Experimental do IAPAR, em Londrina, PR (latitude $23^{\circ} 23^{\prime}$ 'S e longitude $51^{\circ} 11^{\prime} \mathrm{W}$ ) durante a safra 1994/95. O solo é do tipo Latossolo Roxo distrófico, com fertilidade e retenção de água mediana, textura argilosa, boa drenagem, lençol freático muito profundo e baixo teor de matéria orgânica. (Tabela 1). O clima é classificado como subtropical úmido, caracterizado por verões quentes e inverno ameno, com concentração da precipitação durante os meses de verão e decréscimo no inverno. O experimento localizou-se próximo à Estação Meteorológica do IAPAR, de onde foram obtidos os dados climáticos utilizados neste trabalho, incluindo temperatura, precipitação e evapotranspiração potencial calculada pelo método Penman FAO-24 (Doorembos \& Pruitt, 1977).

Foram avaliados a fenologia, a produtividade de grãos e de matéria seca, os componentes de produção, o acamamento e a altura de plantas na colheita de duas cultivares de arroz (IAPAR 64 e IAPAR 9) semeadas em duas épocas (5 de outubro e 1 de dezembro) e submetidas a três regimes hídricos (NI: não irrigado; $\mathrm{I}_{25}$ : irrigação a tensão igual a $25 \mathrm{kPa}$; e $\mathrm{I}_{70}$ : irrigação a tensão igual a $70 \mathrm{kPa}$ ). O delineamento experimental foi em blocos ao acaso, com parcela sub-subdividida, com três repetições, sendo o fator época alocado na parcela, cultivares na subparcela e regimes hídricos na sub-subparcela. Cada unidade experimental teve dimensões de $5 \times 5 \mathrm{~m}$, sendo considerada como bordadura as áreas incluídas a $0,5 \mathrm{~m}$ de cada lateral.

Tabela 1. Características químicas e físicas do solo

\begin{tabular}{|c|c|c|c|c|c|c|c|c|}
\hline \multicolumn{9}{|c|}{ Características Químicas } \\
\hline \multirow[t]{2}{*}{$\begin{array}{l}\text { Profundidade } \\
(\mathrm{cm})\end{array}$} & \multirow[t]{2}{*}{$\begin{array}{c}\mathrm{pH} \\
\left(\mathrm{H}_{2} \mathrm{O}\right)\end{array}$} & \multicolumn{3}{|c|}{$\begin{array}{c}\text { Complexo Sortivo } \\
\text { (cmol } 100 \mathrm{~mL}^{-1} \text { de solo) }\end{array}$} & \multirow{2}{*}{$\begin{array}{l}\mathrm{C} . \\
(\%)\end{array}$} & \multirow{2}{*}{$\begin{array}{c}\mathrm{P} \\
(\mathrm{ppm})\end{array}$} & \multicolumn{2}{|c|}{$\begin{array}{c}\text { Saturação } \\
\text { (\%) }\end{array}$} \\
\hline & & $\mathrm{H}^{+}+\mathrm{Al}^{3+}$ & $\mathrm{Ca}^{2+}+\mathrm{Mg}^{2+}$ & $\mathrm{K}^{+}$ & & & Bases & Alumínio \\
\hline $0-10$ & 5,1 & 4,8 & 7,1 & 0,3 & 1,6 & 4,6 & 61 & 0 \\
\hline $10-40$ & 4,9 & 5,4 & 5,9 & 0,3 & 1,5 & 4,4 & 53 & 1,4 \\
\hline \multirow[t]{2}{*}{$40-100$} & 4,7 & 4,8 & 3,0 & 0,1 & 0,8 & 0,9 & 47 & 3,9 \\
\hline & & \multicolumn{7}{|c|}{ Profundidade $(\mathrm{cm})$} \\
\hline \multirow{2}{*}{\multicolumn{2}{|c|}{ Características Físicas }} & \multicolumn{2}{|r|}{$0-10$} & & \multicolumn{2}{|c|}{$10-40$} & \multicolumn{2}{|c|}{$40-100$} \\
\hline & & \multicolumn{7}{|c|}{ Granulometria $\left(\mathrm{g} \mathrm{kg}^{-1}\right)$} \\
\hline \multicolumn{2}{|l|}{ Areia } & \multicolumn{2}{|r|}{50} & & \multicolumn{2}{|c|}{70} & \multicolumn{2}{|r|}{70} \\
\hline Silte & & \multicolumn{2}{|r|}{130} & & \multicolumn{2}{|c|}{110} & \multicolumn{2}{|r|}{140} \\
\hline \multirow[t]{2}{*}{ Argila } & & \multicolumn{2}{|r|}{820} & & \multicolumn{2}{|c|}{820} & \multicolumn{2}{|r|}{790} \\
\hline & & \multicolumn{7}{|c|}{ Densidade $\left(\mathrm{Mg} \mathrm{t}^{-1}\right)$} \\
\hline \multirow{3}{*}{$\begin{array}{l}\text { Global } \\
\text { Partículas }\end{array}$} & & \multirow{2}{*}{\multicolumn{2}{|c|}{1,14}} & & \multicolumn{2}{|c|}{1,10} & \multirow{2}{*}{\multicolumn{2}{|c|}{1,00}} \\
\hline & & & & & \multicolumn{2}{|c|}{2,78} & & \\
\hline & & & & & lade (L & & & \\
\hline Macroporos & & & 0,45 & & 0, & & & 0,42 \\
\hline Microporos & & & 0,14 & & 0, & & & 0,22 \\
\hline Total & & & 0,59 & & 0, & & & 0,64 \\
\hline & & & & tençã & água & $\left.\mathrm{cm}^{-3}\right)$ & & \\
\hline $10 \mathrm{kPa}$ & & & 0,350 & & 0,3 & & & 0,361 \\
\hline $25 \mathrm{kPa}$ & & & 0,290 & & 0,3 & & & 0,320 \\
\hline $70 \mathrm{kPa}$ & & & 0,259 & & 0,3 & & & 0,301 \\
\hline $1500 \mathrm{kPa}$ & & & 0,202 & & 0,2 & & & 0,272 \\
\hline
\end{tabular}


Todos os tratamentos foram irrigados durante a fase de estabelecimento da cultura, procurando-se manter o solo com tensão acima de $25 \mathrm{kPa}$, para se obter a população de plantas adequada. A necessidade de irrigações foi determinada por tensiômetros de mercúrio, instalados a $15 \mathrm{~cm}$ de profundidade, no centro das sub-subparcelas. Após a emergência da cultura, os diferentes regimes hídricos foram estabelecidos pela aplicação de irrigação, quando se atingiu o nível de tensão preconizado para cada tratamento. Foram aplicadas lâminas para reposição do solo à umidade de capacidade de campo, na camada de 0 a $70 \mathrm{~cm}$, iguais a $30 \mathrm{~mm}$ para o tratamento $\mathrm{I}_{25}$ e $45 \mathrm{~mm}$ para o tratamento $\mathrm{I}_{70}$ correspondendo à reposição de 45 e $65 \%$ da água disponível do solo, respectivamente. As lâminas de irrigação foram calculadas com os dados de retenção de água no solo, apresentados na Tabela 1. As irrigações foram aplicadas por aspersão simulada por uma mangueira acoplada a um crivo metálico com vazão conhecida, sendo interrompidas no estádio de grão farináceo.

A cultura foi semeada em espaçamento de $0,5 \mathrm{~m}$ e densidade de semeadura de 70 sementes $\mathrm{m}^{-1}$, com adubação de $12 \mathrm{~kg} \mathrm{ha}^{-1}$ de $\mathrm{N}, 60 \mathrm{~kg} \mathrm{ha}^{-1}$ de $\mathrm{P}_{2} \mathrm{O}_{5}$ e $30 \mathrm{~kg} \mathrm{ha}^{-1}$ de $\mathrm{K}_{2} \mathrm{O}$, e cobertura de $50 \mathrm{~kg} \mathrm{ha}^{-1}$ de $\mathrm{N}$ no final de perfilhamento. A lavoura foi mantida livre de plantas daninhas, doenças e pragas. A produtividade foi obtida das plantas colhidas na área útil das sub-subparcelas $\left(16 \mathrm{~m}^{2}\right)$ e os componentes de produção e massa seca total (massa seca da parte aérea) de amostras de $1 \mathrm{~m}^{2}$ de cada sub-subparcela, sendo secadas em estufa a $70{ }^{\circ} \mathrm{C}$, até peso constante. A altura de plantas na colheita foi a média das medidas de cinco plantas por parcela, escolhidas ao acaso, e o acamamento foi estimado pela porcentagem da parte acamada, avaliada visualmente, em relação à área total da parcela. A análise de variância e testes de significância dos resultados foram realizados usando-se o programa SAS (Statistical Analysis System; SAS, 1990) e o teste de Tukey foi usado para a comparação das médias.

\section{RESULTADOS E DISCUSSÃO}

Temperaturas abaixo do limiar adequado para o desenvolvimento da cultura (temperaturas mínimas diárias $<17^{\circ} \mathrm{C}$ ) ocorreram em meados de novembro, coincidindo com o início do emborrachamento das plantas da primeira época, e em março, durante o estádio reprodutivo da cultivar de ciclo mais tardio (IAPAR 64) semeada na segunda época (Figura 1). A precipitação excedeu a evapotranspiração potencial em ambos os períodos de cultivo (Tabela 2) e, conseqüentemente, houve boa disponibilidade hídrica, exceto durante curtos períodos de novembro e dezembro, que coincidiram com os estádios emergência-emborrachamento na primeira época e emergênciaperfilhamento na segunda época, e um período seco prolongado em março, durante o estádio reprodutivo dos tratamentos da segunda época (Figura 2). Durante esses períodos foram constatadas diferenças de umidade do solo entre os tratamentos, ocorrendo valores próximos do ponto de murcha permanente nos tratamentos não irrigados e umidade mais elevada nos tratamentos com regime hídrico $\mathrm{I}_{25}$, seguido do $\mathrm{I}_{70}$ (Figura 2).

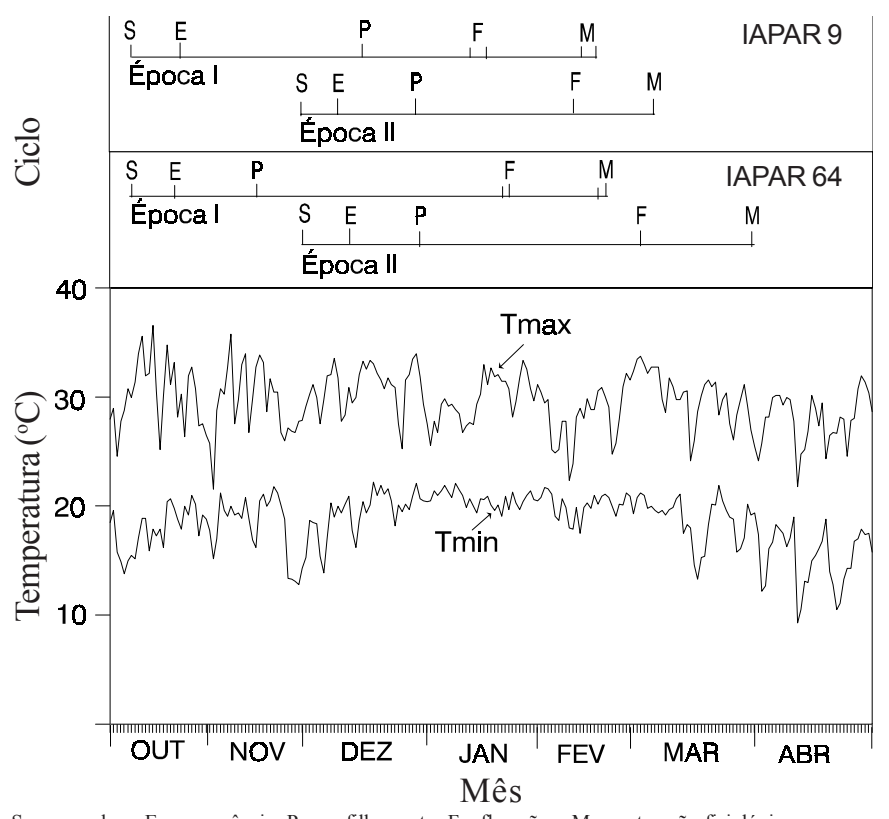

S - semeadura, E - emergência, P - perfilhamento, F - floração e M - maturação fisiológica

Figura 1. Temperaturas máxima (Tmax) e mínima (Tmin) durante as duas épocas de cultivo

Tabela 2. Duração do ciclo de cultivo, totais de precipitação, evapotranspiração potencial (ETP) e número e lâmina de irrigação durante o cultivo de duas cultivares de arroz, de acordo com épocas de semeadura e regimes hídricos

\begin{tabular}{|c|c|c|c|c|c|c|c|}
\hline \multirow[b]{2}{*}{ Época } & \multirow[b]{2}{*}{ Cultivar } & \multirow{2}{*}{$\begin{array}{l}\text { Regimes } \\
\text { Hídricos }\end{array}$} & \multirow{2}{*}{$\begin{array}{l}\text { Ciclo* } \\
\text { (dias) }\end{array}$} & \multirow{2}{*}{$\begin{array}{l}\text { Precipitação } \\
\text { (mm) }\end{array}$} & \multirow{2}{*}{$\begin{array}{l}\text { ETP } \\
(\mathrm{mm})\end{array}$} & \multicolumn{2}{|c|}{ Irrigação** } \\
\hline & & & & & & Número & $\begin{array}{c}\text { Lâmina } \\
(\mathrm{mm})\end{array}$ \\
\hline \multirow{6}{*}{ I } & \multirow{3}{*}{ IAPAR 9} & NI & 123 & 854 & 625 & 0 & 0 \\
\hline & & $\mathrm{I}_{25}$ & 116 & 826 & 594 & 10 & 300 \\
\hline & & $\mathrm{I}_{70}$ & 116 & 826 & 594 & 6 & 270 \\
\hline & \multirow{3}{*}{ IAPAR 64} & NI & 126 & 936 & 635 & 0 & 0 \\
\hline & & $\mathrm{I}_{25}$ & 123 & 854 & 625 & 10 & 300 \\
\hline & & $\mathrm{I}_{70}$ & 123 & 854 & 325 & 6 & 270 \\
\hline \multirow{6}{*}{ II } & \multirow{3}{*}{ IAPAR 9} & NI & 91 & 737 & 441 & 0 & 0 \\
\hline & & $\mathrm{I}_{25}$ & 91 & 737 & 444 & 5 & 150 \\
\hline & & $\mathrm{I}_{70}$ & 91 & 737 & 441 & 2 & 90 \\
\hline & \multirow{3}{*}{ IAPAR 64} & NI & 111 & 802 & 534 & 0 & 0 \\
\hline & & $\mathrm{I}_{25}$ & 111 & 802 & 534 & 9 & 270 \\
\hline & & $\mathrm{I}_{70}$ & 111 & 802 & 534 & 5 & 225 \\
\hline
\end{tabular}

\footnotetext{
Emergência à maturação fisiológica

"* Em adição a $105 \mathrm{~mm}$ aplicados na primeira época e $65 \mathrm{~mm}$ na segunda época para o estabelecimento da cultura
} 


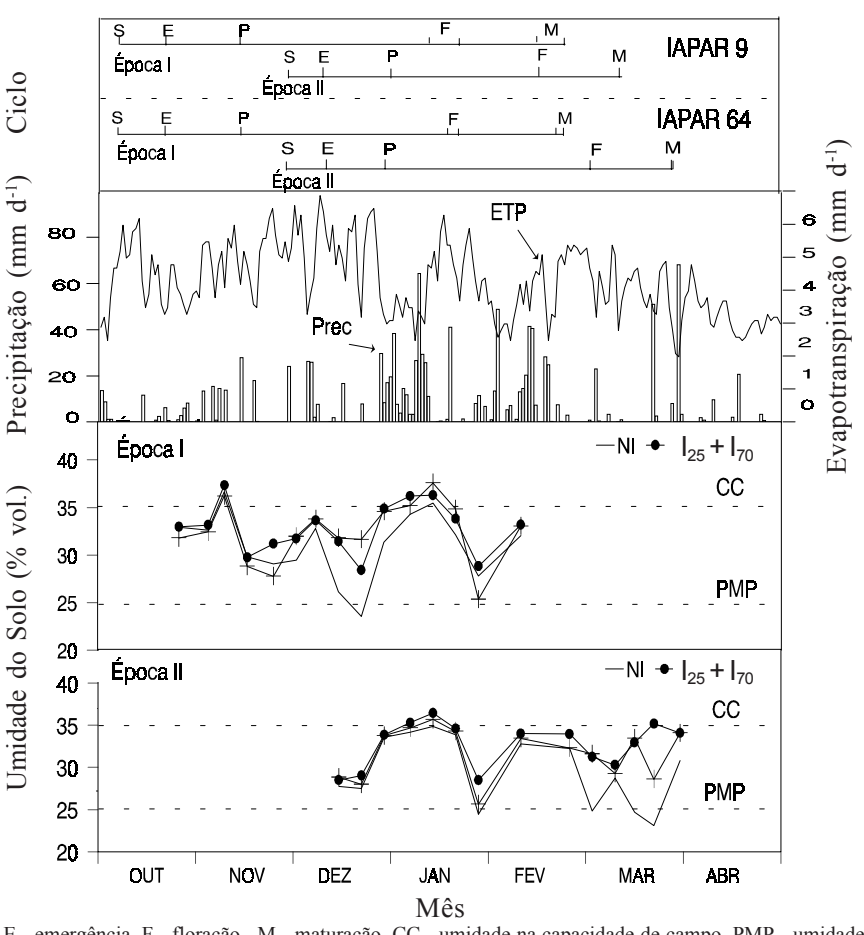

E - emergência, F - floração, M - maturação, CC - umidade na capacidade de campo, PMP - umidade no ponto de murcha permanente

Figura 2. Precipitação, evapotranspiração potencial (ETP) e umidade do solo na camada $10-25 \mathrm{~cm}$, durante as duas épocas de cultivo

O estabelecimento completo da cultura do arroz ocorreu aos 12 dias após a semeadura na primeira época e aos 8 dias após a semeadura na segunda época. Como o perfil se encontrava seco, durante o período semeadura-emergência, foram necessárias três irrigações de $35 \mathrm{~mm}$ nos tratamentos da primeira época e duas irrigações ( 35 e $30 \mathrm{~mm}$ ) nos tratamentos da segunda época.

Embora a precipitação tenha sido menor na segunda época, foram aplicadas maiores lâminas de irrigação na primeira época e, na comparação em cada época, a manutenção dos regimes hídricos preconizados durante a condução dos cultivos semeados na primeira época, demandou maior número de aplicações para os tratamentos sob o regime $I_{25}$ que para os tratamentos com regime $\mathrm{I}_{70}$, porém a lâmina total aplicada foi praticamente a mesma (Tabela 2). Nos cultivos conduzidos na segunda época, houve diferenças no número de aplicações e lâminas, de acordo com os regimes hídricos e cultivares; assim, o tratamento $I_{25}$ recebeu irrigações mais freqüentes e lâmina mais elevada que o tratamento $\mathrm{I}_{70}$, enquanto a cultivar IAPAR 9 recebeu menor suplementação hídrica que a IAPAR 64.

A irrigação mais elevada na primeira época foi atribuída ao ciclo mais longo das cultivares e à demanda atmosférica mais elevada durante dezembro e janeiro, que coincidiu com os períodos de maior crescimento da cultura (Tabela 2, Figura 2). A diferença entre as cultivares na segunda época foi também atribuída à duração do ciclo (Tabela 2, Figura 2) sendo que a cultivar de ciclo tardio (IAPAR 64) necessitou de maior suplementação hídrica que a cultivar precoce (IAPAR 9) porque seu estádio de enchimento de grãos coincidiu com o período de menor precipitação em março. Na primeira época e apesar da diferença de ciclos entre as cultivares, não houve diferença de lâmina aplicada porque, quando foi interrompida a irrigação dos tratamentos com a cultivar IAPAR 9 (estádio de grão leitoso) a precipitação foi suficiente para suprir as necessidades hídricas das plantas da cultivar IAPAR 64, durante a fase de enchimento de grãos.

Em comparação com a primeira época, na segunda época a cultivar IAPAR 9 adiantou o ciclo de desenvolvimento em 24 a 31 dias e a IAPAR 64 em 12 a 17 dias (Tabela 2). A menor duração do ciclo na segunda época foi devido, principalmente, às temperaturas mais elevadas em dezembro e janeiro, que encurtaram o período emergência-perfilhamento em 10 dias, para ambas as cultivares, e o período emergência-floração, em 11 a 21 dias para a IAPAR 9, e 12 a 15 dias para a IAPAR 64. Na comparação entre cultivares, a IAPAR 9 atingiu a maturação fisiológica cerca de 20 dias mais cedo que a IAPAR 64 na segunda época, e 3 a 7 dias na primeira época (Tabela 2). Este fato pode ser atribuído também às diferenças em condições térmicas ocorridas durante o período reprodutivo das cultivares na segunda época e condições térmicas semelhantes na primeira época. Na segunda época, a cultivar mais precoce (IAPAR 9) teve o florescimento em 20/02/95, período coincidente com temperaturas elevadas, enquanto a cultivar mais tardia (IAPAR 64) iniciou o estádio reprodutivo somente em 03/03/95, coincidindo com temperaturas baixas, retardando sua maturação.

Os regimes hídricos afetaram o ciclo das cultivares somente na primeira época, com a deficiência hídrica durante o período vegetativo, retardando a floração nos tratamentos sem irrigação (NI) em 10 dias para a cultivar IAPAR 9 e em 3 dias para a IAPAR 64, resultando em atrasos de 7 e 3 dias no ciclo de desenvolvimento, respectivamente (Tabela 2); já na segunda época o curto período de deficiência hídrica verificado no estádio vegetativo e o longo período ocorrido durante o estádio reprodutivo, não afetaram a fenologia das plantas do tratamento sem irrigação.

A produção de grãos (Figura 3) foi significativamente mais elevada na primeira época ( 5400 a $\left.6000 \mathrm{~kg} \mathrm{ha}^{-1}\right)$ em comparação com a segunda época (1600 a $4800 \mathrm{~kg} \mathrm{ha}^{-1}$ ) em conseqüência das baixas temperaturas durante o período reprodutivo e menor duração do ciclo de desenvolvimento da época II. A cultivar IAPAR 9 apresentou produtividade significativamente superior à da IAPAR 64 na segunda época, porém não houve diferenças na primeira época; aquela, de ciclo mais curto, desenvolveu-se sob melhores condições de temperatura durante o período reprodutivo que a IAPAR 64, de ciclo mais longo (Figura 1). Como houve boa disponibilidade hídrica durante os estádios críticos da primeira época, a produção de grãos foi afetada pelos regimes hídricos somente na segunda época, ocorrendo decréscimo de cerca de $50 \%$ no tratamento sem irrigação em relação aos tratamentos irrigados, embora não tenha havido diferenças entre estes devido, talvez à boa disponibilidade hídrica durante o emborrachamento-floração. 

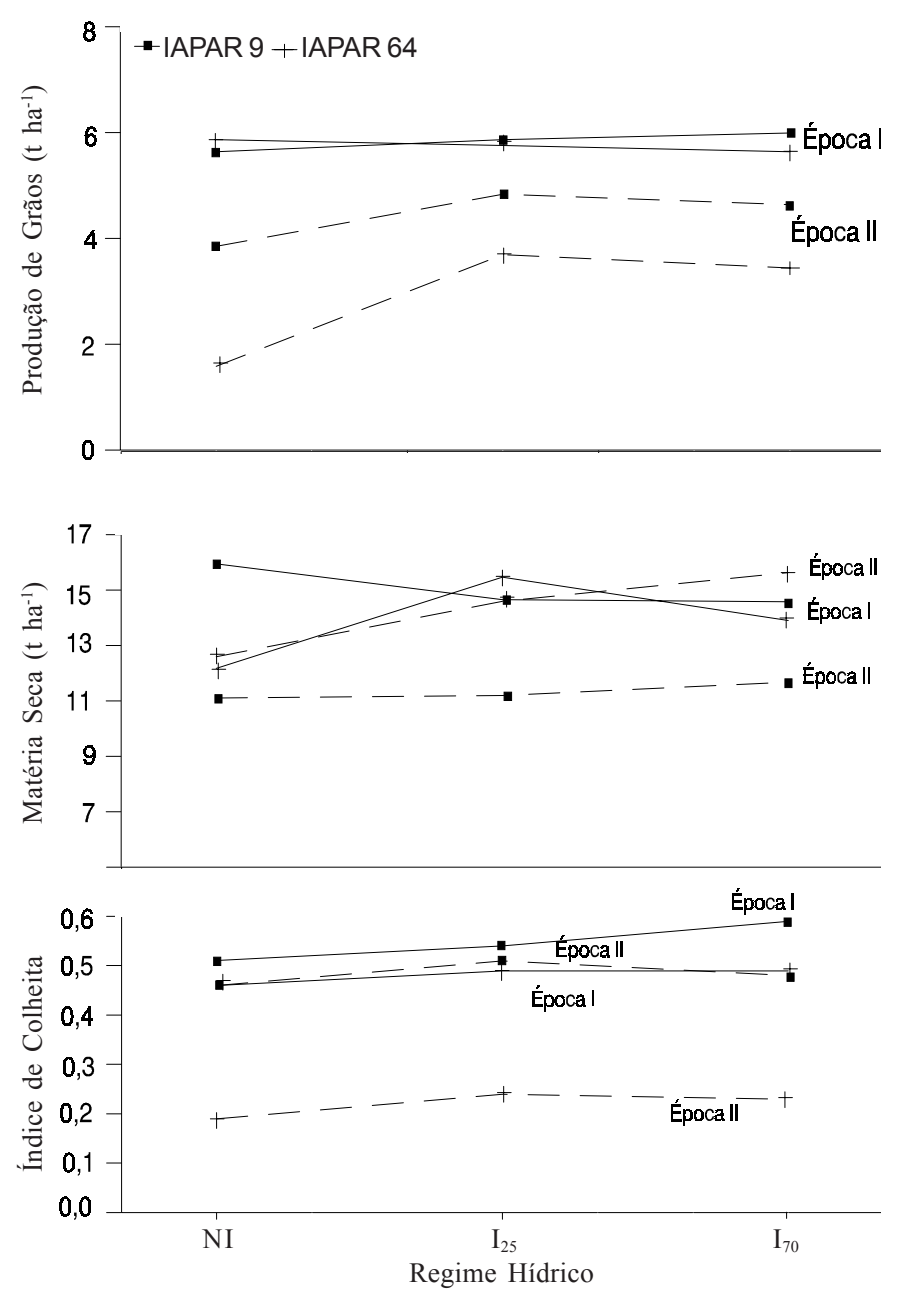

Figura 3. Produção de grãos, produção de matéria seca e índice de colheita de duas cultivares de arroz submetidas a três regimes hídricos, durante duas épocas de semeadura, em Londrina, PR

A produção de massa seca da cultivar IAPAR 9 foi elevada na primeira época e decresceu significativamente na segunda época, enquanto a produção de massa seca da IAPAR 64 se manteve estável nas duas épocas de semeadura, sendo semelhante à da IAPAR 9 na primeira época e significativamente superior na segunda época (Figura 3). A cultivar IAPAR 9 não apresentou resposta ao fator regime hídrico, enquanto a IAPAR 64 apresentou valores significativamente superiores nos tratamentos irrigados, em relação à testemunha.

Os valores de índice de colheita variaram ao redor de 0,5 para todos os tratamentos, exceto para os da cultivar IAPAR 64 na primeira época. Nesses tratamentos, a relação da produção de grãos pela massa seca foi mais baixa que a das demais, porque as plantas apresentaram bom desenvolvimento vegetativo, com produção de massa seca semelhante aos demais tratamentos, porém as baixas temperaturas ocorridas durante o período reprodutivo causaram decréscimo da produção de grãos.

Os efeitos dos tratamentos nos componentes de produção são ilustrados na Figura 4. Não foi observado efeito significativo do regime hídrico no número de espigas por área, porém houve efeito de épocas de semeadura e cultivares; assim, as médias da primeira época e a da cultivar IAPAR 64 foram estatisticamente superiores às obtidas na segunda época e com a cultivar IAPAR 9 , respectivamente. Na análise do número de grãos por espiga, não houve efeitos de época e regime hídrico, porém a cultivar IAPAR 9 apresentou valores estatisticamente superiores em comparação com a IAPAR 64. O menor número de grãos por espiga da cultivar IAPAR 64 foi compensado pela maior média de massa de sementes em relação à determinada para a IAPAR 9. A massa de sementes foi também afetada pela época de semeadura, ocorrendo maiores médias na primeira época, e regime hídrico, observando-se maiores médias no nível $\mathrm{I}_{25}$, seguido do $\mathrm{I}_{70}$ e, finalmente, NI.

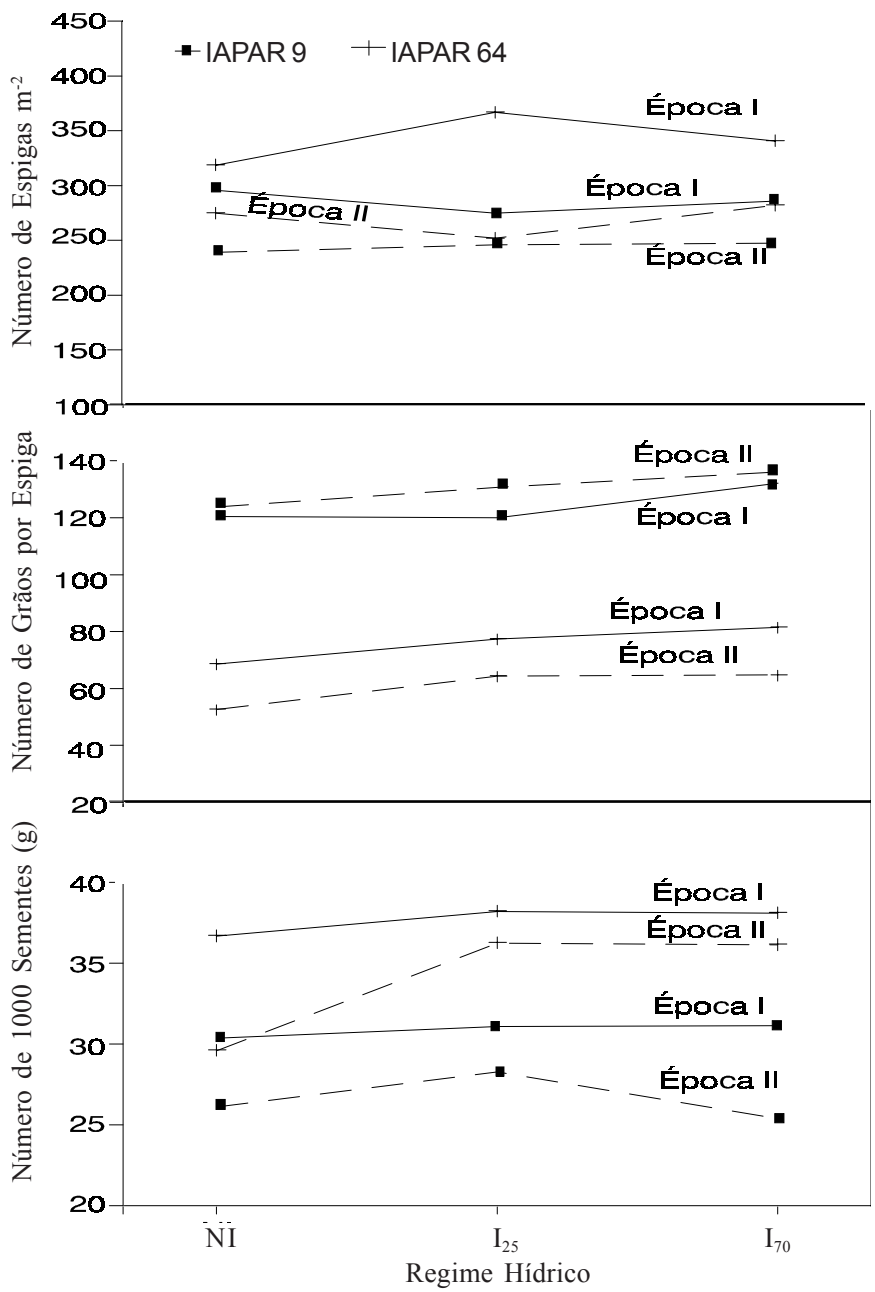

Figura 4. Componentes de produção de duas cultivares de arroz submetidas a três regimes hídricos, durante duas épocas de semeadura, em Londrina, PR

Os valores de altura de plantas na colheita e níveis de acamamento ocorridos em função dos tratamentos, são apresentados na Figura 5. Não houve efeitos de época de semeadura e regime hídrico na altura das plantas, porém a cultivar IAPAR 9 foi significativamente mais alta que a IAPAR 64; conseqüentemente, observou-se maior acamamento nos tratamentos com aquela cultivar, sendo este significativamente superior nos tratamentos irrigados. $\mathrm{O}$ acamamento ocorreu principalmente durante as aplicações de irrigação, por ocasião do estágio final de grão leitoso, devido ao aumento do peso da parte aérea pelo molhamento do dossel. 


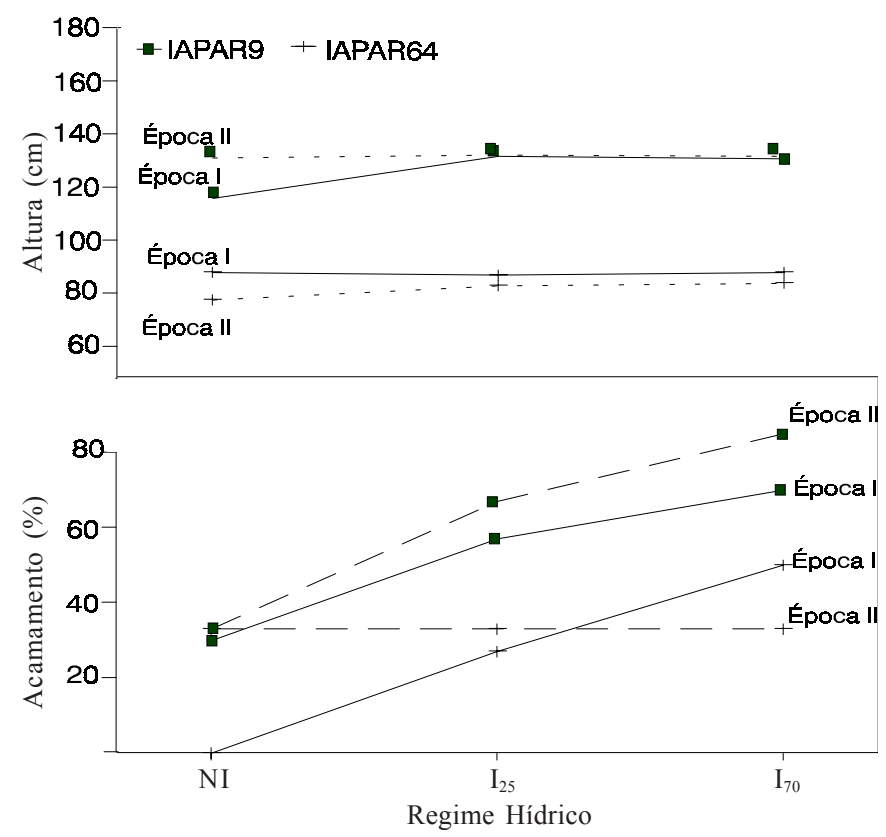

Figura 5. Altura de plantas na colheita e acamamento de duas cultivares de arroz submetidas a três regimes hídricos, durante duas épocas de semeadura, em Londrina, PR

\section{CONCLUSÕES}

1. O arroz apresentou produtividade elevada no norte do Paraná, constituindo-se numa alternativa altamente promissora para sucessão de culturas em projetos de irrigação da região.

2. A produtividade foi mais elevada na semeadura em outubro que na de dezembro, que foi limitada por baixas temperaturas, no final do ciclo de cultivo.

3. A comparação de cultivares revelou que a IAPAR 9 tem as vantagens de requerer menor suplementação hídrica, pela sua precocidade, e também por poder ser semeada em época mais tardia que a IAPAR 64; sua altura mais elevada é uma desvantagem, por provocar maior acamamento quando o cultivo é conduzido sob irrigação plena.

\section{LITERATURA CITADA}

Caramori, P.H.; Faria, R.T. de. Frequência de períodos de 10 dias consecutivos com deficiência hídrica (veranicos) para Londrina e Ponta Grossa. Londrina: IAPAR, Boletim Técnico n.20, 1987.24p.

De Datta, S.K. Principles and practices of rice production. New York: John Wiley \& Sons, 1981.

De Datta, S.K.; Chang, T.T.; Yoshida, S. Drought tolerance in upland rice . In: Major research in upland rice. Los Baños: International Rice Research Institute. 1975, p.101-116.

Doorenbos, J.; Pruitt, W.O. Guidelines for predicting crop water requirements. 2.ed. Rome: FAO, 1977. 156p. FAO Irrigation and Drainage Paper, 24

Ekanayake, I.J.; Steponkus, P.L.; De Datta, S.K. Sensitivity of pollination to water deficits at anthesis in upland rice. Crop Science, Madison, v.30, n.2, p.310-315, 1990.

Faria, R.T. de; Folegatti, M.V.; Frizzone, J.A; Saad, A.M., Determination of a long-term optimal irrigation strategy for dry beans in Parana State, Brazil. Scientia Agricola, Piracicaba, v.54, número especial, p.155-164, 1997.

IAPAR - Instituto Agronômico do Paraná. Cultura do arroz no estado do Paraná. Londrina: IAPAR, 1980. 62p. Circular 19

Novero, R.P.; O’Toole, J.C.; Cruz, R.T.; Garrity, D.P. Leaf water potential, crop growth response, and microclimate of dryland rice under line source sprinkler irrigation. Agricultural and Forest Meteorology, Amsterdam, v.35, p.71-82, 1985.

Santos, A.B.; Costa, J.D. Comportamento de variedades de arroz de sequeiro em diferentes populações de plantas, com e sem irrigação suplementar. Scientia Agricola, Piracicaba, v.52, n.1, p.1-8, 1995.

SAS. SAS Procedures Guide, Version 6. 3.ed. Cary, NC: SAS Institute Inc., 1990. 705p.

Vieira, A.R.R.; Steinmetz, S.; Brunini, O. Parâmetros de crescimento de duas cultivares de arroz sob diferentes regimes de água no solo. Pesquisa Agropecuária Brasileira, Brasília, v.25, n.6, p.897-904, 1990. 